\title{
Transformaciones del Cuerpo en Psicología Social
}

\author{
Alejandra Araiza ${ }^{1}$ \\ Gustavo Gisbert \\ Universidad Autónoma de Barcelona
}

\begin{abstract}
RESUMEN - En el presente ensayo buscamos aproximarnos brevemente a algunas de las transformaciones que ha vivido el cuerpo dentro del conocimiento, centrándonos en los grandes cambios que han podido reflejarse en las teorías dentro de la Psicología, particularmente dentro de la Psicología Social. Quisiéramos más que nada acercarnos a la especial relación que se genera entre las transformaciones sociales, los cambios en el conocimiento científico y los dispositivos tecnológicos en las formas de comprensión de la corporeidad humana, procurando entender al cuerpo de una forma no estática, sino como un continuo devenir.
\end{abstract}

Palabras-clave: cuerpo; conocimiento; psicología social; sujeto.

\section{Conceptual Transformations of the Body in Social Psychology}

\begin{abstract}
This paper is an approach to some body's transformations rooted on psychology theories, particularly social psychology and social construccionism. Our goal is to focus on the relationship between social transformations, scientific knowledge changes and technological regimes of knowledge and power (dispositifs) on ways to understand human body. We try to regard the body not as a static phenomenon but as a becoming.
\end{abstract}

Key words: body; scientific knowledge; social psychology; subject.

\section{Transformações do Corpo em Psicologia Social}

\begin{abstract}
RESUMO - No presente ensaio busca-se uma aproximação breve de algumas das transformações que o conceito de corpo tem sofrido dentro do conhecimento centrando-se nas grandes mudanças que têm se refletido nas teorias dentro da Psicologia, particularmente dentro do construcionismo social e da Psicologia Social em geral. Uma atenção especial será dada à relação que se gera entre as transformações sociais, as mudanças no conhecimento científico e os dispositivos tecnológicos nas formas de compreensão da corporeidade humana, procurando entender o corpo de uma maneira não estática, mas sim, como um contínuo devir.
\end{abstract}

Palavras-chave: corpo; conhecimento; psicologia social; sujeito.

El reciente desarrollo de innumerables tecnologías biomédicas nos ofrecen la posibilidad de transformar el cuerpo hasta lo impensable. Es el caso de las cirugías cosméticas, los transplantes de órganos, las tecnologías transexuales, la psicofarmacología, manipulación de genes, entre muchas otras. Estas tecnologías han acentuado la idea del "multiple choice": libertad de posibilidades de cambiar no sólo nuestra imagen, sino nuestras formas de vida, nuestro proyecto de quiénes somos.

El cuerpo se transforma en una especie de mensaje que se escribe, se lee, se transcribe, se borra y se reescribe constantemente. Resulta - usando una metáfora de la informática - casi un programa de código abierto a la intervención. En él

1 Endereço: Departament de Psicología Social, Passeig de la Vall d'Hebron, 171, Barcelona, España 08035. E-mail: alearaidi@yahoo. com se inscribe una conformación bio-política basada en el control-estimulación, bajo la forma de un menú a la carta que puedes escoger libremente: tienes más opciones para hacer hasta lo inimaginable. Nuestra vida física y psíquica parece - quizás hoy más que nunca - guiada por esta compleja red de biotecnologías y sabidurías del cuerpo: bioquímica de regulación de las emociones, body building, dietética, cirugía estética, mercadotecnia y farándula de culto a la imagen del cuerpo, por sólo mencionar algunos temas.

Las nuevas tecnologías en esta era informática, han transformado completamente nuestras relaciones y nuestra forma de comprender la corporeidad. Las telecomunicaciones hoy en día hacen que podamos estar a la vez aquí y allá. Del otrora tradicional límite del cuerpo que era la piel, con los rayos X, los escáneres, sistemas de resonancia magnética, tomografías y cámaras de emisión de positrones se virtualiza la superficie del cuerpo, la frontera del límite ya no existe (Levy, 1998). La reconstrucción o la imagen del cuerpo por dentro no implica dolor ni muerte (hasta 
podemos saber el sexo y ver el rostro de los niños antes de haber nacido). Una vez virtualizado el cuerpo se vuelve permeable, sujeto además a múltiples transformaciones. El cuerpo sale de sí mismo, adquiere nuevas velocidades, otros espacios.

La metáfora del cuerpo social se vuelve una experiencia real: la sangre se encuentra depositada en bancos de intercambio, así como los óvulos, los espermas, los órganos. Pero también se nos hacen injertos y prótesis de animales, minerales o inclusive hormonas producidas por bacterias (Levy, 1998).

En efecto, todas esas tecnologías que están involucradas en el hacer o rehacer al cuerpo en su materialidad, también se encuentran al servicio de producir nuevas formas de subjetividad. Estas formas mantienen un soporte económico y político en el mercadeo de estas prácticas biotecnológicas, $\mathrm{y}$ han generado poderosas y nuevas maneras de fabricar sujetos en la cultura occidental durante los últimos siglos.

También encontramos movimientos sociales que tratan de ofrecer resistencias, neo-tribus o contraculturas que buscar alejarse de las formas usuales del control-estimulación. Es el caso, por ejemplo, de los queers, los grupos que practican el cutting, los neogóticos, las anoréxicas, entre muchos otros. Estas minorías juegan un papel periférico, pero fundamental en las nuevas transformaciones de la comprensión de la corporeidad. Sin embargo, quedan engullidos rápidamente dentro de la biopolítica del cuerpo.

En síntesis y sin lugar a dudas, los avances de la medicina y la biología han cambiado completamente nuestro mapa-mundi de la corporeidad. Y se nos abre una serie de interrogantes casi obligatoria ante este escenario de lo que ocurre en el mundo: ¿qué ocurre con la psicología social teórica en este sentido?, ¿cómo se ha ido transformando el cuerpo dentro de la psicología social?, ¿podemos pensar en nuevas teorías sociales del cuerpo o la corporeidad?

Las formas de ver al cuerpo dicen mucho de los modelos de comprensión de la realidad que nos orientan, así como de la simbólica general del mundo que tenemos. No en vano, algunos autores plantean la idea de que es posible comprender la historia de las diversas sociedades humanas tan sólo investigando sus concepciones acerca del cuerpo (Bernard, 1985; Le Breton, 1995).

En este sentido surge la inquietud con respecto a las formas de comprensión de la corporeidad que se mueven en los contextos académicos. Estas formas en las que habita el conocimiento académico-científico no son necesariamente muy explícitas, y en ocasiones hasta suelen pasar desapercibidas.

El tema de la corporeidad es muy amplio y complejo en el conocimiento científico, y ciertamente no existe una sola mirada. Pasamos nuestra formación en la universidad contemplando diversidad de enfoques que plantean - implícita o explícitamente - cómo participa (o deja de participar) el cuerpo en la ciencia psicológica. Desde las raíces filosóficas de la psicología hasta nuestros días, muchas son las teorizaciones sobre el tema. Y las variaciones no son sólo diacrónicas, sino también sincrónicas. Las transformaciones, transmutaciones o metamorfosis de las teorizaciones del cuerpo son territorios muy vastos, pero también muy fértiles, de los que surgen cuestionamientos importantes.
Consideraremos a continuación algunos hitos en estas transformaciones. Una pequeña salvedad antes de comenzar: es evidente que estos hitos tienen algo de arbitrarios, y que los cambios que reflejan son fluidos y sus fronteras siempre borrosas. Los tomaremos aquí como una estrategia didáctica que nos será de utilidad a la hora de pensar y analizar las transformaciones del cuerpo en nuestros contextos académicos y no como algo que demos por definitivo, ni como una clasificación rígida e inflexible.

El objetivo del presente ensayo es realizar una revisión teórica del concepto de cuerpo en la cultura occidental, que se iniciará con los postulados de Platón sobre la división mente-cuerpo hasta las concepciones postestructurlistas, socioconstruccionistas y feministas del cuerpo. La idea es sistematizar estas teorizaciones para delimitar un campo de interés que consideramos relevante cuando se pensa en psicología.

\section{La Tradición Dualista Occidental}

\section{La división alma (psique)-cuerpo}

El nacimiento de la psicología como ciencia se establece casi por consenso en nuestra tradición cientificista en Leipzig, Alemania, con la psicología experimental de Wilhelm Wundt. Sin embargo, no es poca la importancia que se le adjudica también al largo periodo de gestación que tuvo la psicología de la mano de la filosofía occidental. De la antigua filosofía griega, así como de la filosofía escolástica medieval y renacentista, se han heredado gran cantidad de nociones de fundamental importancia en la comprensión teórica del cuerpo; pero también (y quizás más importantes) en las concepciones tácitas o implícitas de la corporeidad. El primer hito del cual hablaremos es, entonces, el de la tradición dualista occidental. ¿A qué nos referimos con el término "tradición dualista"? En su acepción más usada, el dualismo habla de la oposición que se plantea entre lo inmaterial y lo material, concretamente en la antinomia entre el alma (o bien psique) y el cuerpo. Estos dos polos orientan la comprensión de la realidad del mundo filosófico y religioso de la antigua Grecia. Y desde aquellos tiempos, se conservan muchos aspectos, que se repiten o se mantienen; si bien algunos se han transformado por completo, es posible afirmar que esta antinomia dualista aún vive con mucha fuerza dentro de nuestras tradiciones.

La alegoría de la caverna de Platón es la imagen que con mayor claridad nos deja apreciar estos sentidos: nos dibuja un mundo material, de cuerpos finitos y perecederos, que es donde viven los humanos (la caverna) en donde se refleja el movimiento de sombras engañosas y realidades aparentes. La verdad se esconde detrás de las sombras, y está en otra dimensión: fuera de la caverna, donde está el mundo de la luz, lo bello y lo bueno. Sólo el filósofo, a través del conocimiento y el método filosófico puede salir de la caverna para mostrar luego la verdad a los demás (Platón, 1993). Esta imagen sin duda recoge algunas nociones de gran importancia sobre la comprensión de la corporeidad para la filosofía antigua: a pesar de ser grandes cultores de la gimnasia y la estética, existe desde los griegos un gran desdén por la materialidad del cuerpo, y esto es muy notorio 
en las academias y en la conformación del conocimiento. Y podríamos agregar no sólo del cuerpo en sí, sino del cuerpo en su relación con el mundo de objetos. El cuerpo es en principio lo que nos acerca a las sombras, a lo animal, a lo "irracional", y por eso hay que trabajarlo rigurosamente, dominarlo. En cambio, el mundo del alma es el mundo de las ideas, de la inmortalidad, lo infinito no perecedero, le perfecto y lo bello; el mundo de la geometría euclideana, el mundo platónico, mundo que tanto ha marcado a la concepción heredada de las ciencias y a las sociedades occidentales.

Escudriñando sobre los primeros rastros de la psicología social en la filosofía antigua, el propio Platón también hablaba sobre la multitud; decía que incluso los individuos más sabios al unirse y formar parte de una multitud podrían transformarse en una turba irracional (Smith, 1990). La idea de que el cuerpo social es algo que está fuera de la racionalidad, y que puede arrastrar o influenciar negativamente hasta al más "sabio", cobra aquí un valor del que no le será nada fácil salir con el transcurrir del tiempo, tanto dentro como fuera de la psicología social.

Cabe decir además que todo el peso de la historia de las religiones (fundamentalmente las tres principales en la historia occidental: la cristiana, la judía y la musulmana) ha contribuido enormemente a mantener presente en nuestras sociedades esta división alma (psique)-cuerpo, en la que se refuerza el privilegio del dominio de la primera sobre el segundo.

\section{División mente-cuerpo}

Otro hito importante que podemos destacar es el nacimiento de la medicina moderna y el del interés de la ciencia por conocer la conformación anatómica y fisiológica del cuerpo humano. La búsqueda del conocimiento del cuerpo como objeto podríamos decir que constituye una de las semillas de la cual surgen las ciencias experimentales y de laboratorio. El interés por el cuerpo como objeto de conocimiento se aprecia con gran claridad en diversos autores incluso desde antes del renacimiento; sin embargo, es probable que ninguno de ellos haya tenido tanta repercusión en la historia del conocimiento como René Descartes.

A Descartes, entre muchas otras cosas, se le considera precursor de la psicofisiología. Además de sus famosas tesis y meditaciones, logró materializar la interacción entre el reino de la mente y el del cuerpo en la glándula pineal. Por lo general, en aquella época no era muy difícil diferenciar el reino de la realidad mental (el mundo del pensamiento, la voluntad, la virtud) de la realidad de los cuerpos (las respuestas fisiológicas, actos reflejos, entre otros). Sin embargo, se generaban estados confusos como el hambre o la sed: estos estados ponían de manifiesto que las necesidades corporales podían estar interconectadas con la voluntad, y esto era posible, según Descartes, gracias a la glándula pineal que conectaba ambos mundos.

No obstante, lo más importante de la tesis cartesiana es, sin lugar a dudas, su res cogitans. A través de la duda metódica, logra fundar toda su filosofía sobre una certeza inamovible: cogito ergo sum, es el pensamiento que precede la existencia, la conciencia y por ende el mundo de la mente y de la reflexividad prevalece sobre el mundo de los sentidos y la existencia. Este aspecto, tan arraigado en nuestras tradiciones, es una de las razones por las cuales en nuestras sociedades occidentales la mente es privilegiada con respecto al cuerpo: el centro es el sujeto racional, y éste no es su cuerpo.

Podemos incluso observar una noción de cuerpo instrumental: el cuerpo como instrumento de la mente. Esta imagen de instrumento funcional se ha ido transformando, de acuerdo a los cambios tecnológicos y científicos de cada época: del cuerpo máquina de la revolución industrial al cuerpo ciber virtualizado de nuestros tiempos.

Cabe destacar también la comprensión de las formas de gobierno como metáforas del cuerpo que se han mantenido a lo largo del tiempo. La sociedad, desde la filosofía antigua, se ha convertido en un cuerpo con una cabeza que lo gobierna, dirige y disciplina. El cuerpo social debe ser igualmente dominado por la cabeza que lo gobierna, que lo conduce hacia el bien o hacia el mal.

Con el nacimiento de la medicina moderna, la metáfora del cuerpo social se transforma en un organismo más complejo, en el cual las desviaciones de las normas se comprenden como enfermedades contra las que se debe luchar.

\section{Paralelismo psicofísico}

El paralelismo psicofísico - el marco en el cuál se fundamentan los primeros planteamientos científicos de la psicología experimental - tiene su punto de apoyo en sus desarrollos sobre la relación e interacción entre el mundo físico y el mundo psíquico: al terreno de la realidad mental le debía corresponder su debida equivalencia en la realidad "objetiva" de los cuerpos. Este cuerpo objetivado al que se le suscriben procesos psíquicos paralelos es sin lugar a dudas el sostén del positivismo lógico y la psicología moderna.

A finales del siglo XIX, influidos enormemente por los métodos de laboratorio usados por los fisiólogos, Wundt y otro gran grupo de investigadores comenzaron a utilizar técnicas experimentales para medir procesos mentales, como la senso-percepción, la memoria, los tiempos de reacción o el juicio. Las primeras referencias de la Psicología Social dentro de la concepción heredada de las ciencias comienzan con la investigación experimental también por aquella época, cuando investigadores en EEUU, Francia e Inglaterra comenzaron a medir la influencia de la presencia de los demás en el comportamiento de los seres humanos.

Desde aquellas investigaciones preliminares han transcurrido grandes cambios, no sólo en el mundo científico sino también en el mundo tecnológico y social. La idea de un paralelismo psicofísico, de la mente como un espejo de la naturaleza - utilizando la metáfora de Rorty - no es algo fácil de sostener en la psicología social contemporánea. No obstante, lo que quisiéramos destacar en este apartado es que desde la era cartesiana hasta la modernidad tardía, la "psique" ha adquirido tanta preponderancia - en especial con el concepto de reflexividad - y se ha acelerado de manera tal que el cuerpo, una vez dado como aspecto de la naturaleza, se convierte en un proyecto abierto a la intervención humana, y, como la naturaleza, es colonizado y sujeto a constante revisión. 


\section{El dominio del conductismo y cognoscitivismo}

El desarrollo de la psicología en el siglo XX está marcado sin lugar a dudas por dos grandes corrientes teóricas: el conductismo y el cognoscitivismo (sin menospreciar al psicoanálisis y al humanismo). Todavía hoy en día resuenan con fuerza dentro de la psicología actual - también dentro de la psicología social - algunos principios de estas teorías.

El modelo biologicista causal Estimulo-Respuesta (ER) que planteaba el conductismo de principios del siglo pasado, fue adquiriendo ciertos matices, hasta sufrir una importante transformación con las teorías cognoscitivas de la segunda mitad del siglo, al introducir en el medio del E-R al Organismo (E-O-R) que procesa la información externa. La conducta de las personas y el organismo que procesa información nos ofrecen unas visiones sobre el cuerpo muy interesantes: en la primera el cuerpo sólo es algo que reacciona frente a determinados estímulos y que tiene cierta capacidad de aprendizaje; en la segunda nos ofrece una imagen de cuerpo-computadora, que tiene un input sensorial, que recibe en su interior esos estímulos y gracias a ellos se producen algunos procesos y posteriormente se genera un output, en el comportamiento. Es en esta última metáfora del cuerpo-computadora donde es posible apreciar con mayor claridad la influencia de la tecnología y del mundo social en la construcción del conocimiento científico: con el auge de la informática y las computadoras, las teorías psicológicas dieron un giro notable.

Frente a estos grandes paradigmas, surgieron profundas críticas desde otros modelos de la psicología. Así, por ejemplo, en el incipiente terreno de la psicología social, el interaccionismo simbólico y la etnometodología reclamaban la agencialidad del sujeto: el cuerpo no es algo inmóvil que sólo reacciona al mundo externo. En efecto, buscaron rescatar la agencialidad y originalidad del ser humano, esa vía media que conecta el individuo con el mundo por medio de la significación de sus actos. Lo más relevante de estas teorías fue el considerar el proceso interpretativo y de significación humano como una nueva manera de aproximarse al yo o sí mismo, desde la acción conjunta, la intersubjetividad o bien el discurso de lo cotidiano (Blumer, 1982). También la etnometodología ha aportado grandes avances en este sentido (Garfinkel, 1967).

Los psicólogos atribuyen determinadas formas o ejemplos de comportamiento humano a factores tales como estímulos, actitudes, motivaciones conscientes o inconscientes, diversos tipos de input psicológico, percepción y conocimiento, y distintos aspectos de la organización personal. De modo parecido, los sociólogos basan sus explicaciones en otros factores, como la posición social, exigencias del status, papeles sociales, preceptos culturales, normas y valores, presiones del medio, afiliación a grupos. (Blumer, 1982, p. 2)

El interaccionismo simbólico buscaría situarse en otro lugar, fuera de estos dos extremos psicologicistas o sociologicistas, y centrar la significación en la interacción de las relaciones, vía la interpretación y el lenguaje. Esto marca una pauta hacia el predominio de la reflexividad.

\section{La interacción Cuerpo-Mundo de la Fenomenología}

La fenomenología de Heidegger (1929/2003) así como los planteamientos de Merleau-Ponty (1975) abren una nueva brecha para la comprensión de la corporeidad.

El cuerpo para Merleau-Ponty (1975) es el vehículo de estar-en-el-mundo. A su vez, la conciencia del propio existir corporal quedaría expresado de la siguiente manera: "Tener un cuerpo significa para un ser vivo volcarse en un medio definido, confundirse con ciertos proyectos y emprender continuamente algo" (Merleau-Ponty, 1975, p. 97). "El cuerpo está, pues, abierto a lo nuevo [...] es decir, al espacio y al tiempo de suerte que el cuerpo los "habita" antes que estar incluido y encerrado en el tiempo y el espacio." (Bernard, 1985, p. 71).

Así nuestro cuerpo puede percatarse de que es, en un mismo momento, cuerpo que ve y es visible, que toca y es tocado, forma parte del mundo y a la vez le da existencia.

Tal como plantea Merleau-Ponty (1975), lo que aparece fenomenológicamente no puede ser ni interior ni exterior, tampoco es apriorísticamente verdadero o falso. Es una fuerte crítica a la tradición dualista occidental, que busca negarle el derecho de ciudadanía al esencialismo de creer en un "verdadero hombre interior" diferenciado de su "fachada falsa" que lo encubre. El "entre-deux" Merleau-pontyano, significa integración y relación entre lo "originado" y lo "originante" en el acontecimiento de la existencia, del mundo en el cuerpo y el cuerpo en el mundo.

\section{Del Cuerpo a la Biopolítica}

\section{La visión postestructuralista}

Gran parte de los aportes al estudio contemporáneo de la corporeidad en nuestro terreno provienen del postestructuralismo, con base en escritos claves de Foucault (1976) y conceptos tales como dispositivo de la sexualidad o biopolítica. No obstante, conviene revisar también el artículo McNay (1999), donde compara las aportaciones al estudio del cuerpo de Foucault (1976) y el postestructuralismo con las de Bourdieu (1979/1988), cuyo punto de partida es más bien estructuralista. Es así -dice la autora- que mientras Foucault (1976) habla de sujetos desde una concepción atemporal (se refiera a la idea foucaultina de de tabula rasa, del cuerpo como lugar de inscripción de estructuras institucionales); Bourdieu (1979/1988) habla de agencias sociales desde una mirada temporal útil para la comprensión del cuerpo. Foucault (1976) considera que la voluntad es suficiente para transformar las prácticas individuales; mientras que la idea bourdiniana es la de una agencia corporal de fundación prerreflexiva que no es inmediatamente transformable por el yo. Según Foucalut (1976), la formación de la subjetividad siempre conlleva una sujeción al sistema de dominación; mientras que para Bourdeiu (1979) la dominación siempre conlleva resistencia.

El cuerpo para Foucault (1976) es lugar de resistencias, constructo de epistemes, y sobre todo nudo de estrategias de poder. Así, por una parte, hay que atender - como advierte Rodríguez (1999) - tanto a la idea de sexo, como a 
la de biopolítica. En cuanto a la primera, Foucault (1976) establece cuatro grandes frentes: la histerización del cuerpo de la mujer, pedagogización del sexo del niño, socialización de las conductas procreadoras y psiquiatrización del placer perverso. Ello a partir de la puesta en marcha de lo que él denomina dispositivo de la sexualidad. Si consideramos que por dispositivo, Foucault (1976) concibe: "un conjunto decididamente heterogéneo, que comprende discursos, instituciones, instalaciones arquitectónicas, decisiones reglamentarias, leyes, medidas administrativas, enunciados científicos, proposiciones filosóficas, morales, filantrópicas" (Foucault en Rodríguez, 1999, p. 205).

De esta forma, el dispositivo para la sexualidad acaba generando la idea de sexo. Pero como el sexo no es el reducto liberador frente a la ley sino uno más de sus efectos, habría que profundizar en los cuerpos y los placeres, porque para él es el cuerpo el foco persistente del ejercicio disciplinario.

$\mathrm{Y}$ con ello también nos presenta una perspectiva desde la que se concibe el control del cuerpo con efectos a un nivel más macro. Esto desde su concepto de biopoder, que se encarga del control de las poblaciones. La ejecución de este biopoder tiene dos implicaciones. Por un lado, el discurso científico atraviesa lo humano: invasión del cuerpo. Y, por otro, la ley se ve sobrepasada por la norma (Foucault, 1976).

Pero también es desde este cuerpo, decíamos, que se crea la resistencia. El cuerpo es, en síntesis:

el punto de partida de nuestra incardinación material en el mundo, metabólico reducto de certezas sensitivas, umbral de dolor, placer o plenitud, complejo dinámico que no se descubre, sino que se construye en la interacción con las estrategias de poder-saber que sobre él se vierten, lo definen, lo escrutan, lo disciplinan... y a las que él responde plegándose, reconociéndose, hurtándose (Rodríguez, 1999, p. 216).

\section{El Cuerpo es Discurso}

\section{Aportes del socioconstruccionismo}

Con la conformación del giro lingüístico, el sujeto racional y reflexivo devino en sujeto hermenéutico, es decir, en sujeto que se produce a sí mismo a través del lenguaje. En efecto, en nuestros contextos académicos ahora es el discurso quien produce al sujeto.

Así, puede decirse que la visión socioconstruccionista parte de la necesidad de deconstruir la ciencia moderna y posicionarse dentro de un contexto determinado.

No obstante, aun cuando nos parece que el socioconstruccionismo pueda establecer una nueva manera de concebir al sujeto, no podemos pasar por alto algunas críticas que - desde el feminismo - se le han hecho, especialmente a ciertas posturas socioconstruccionistas consideradas muy discursivos como lo son el de Potter (2000) y Edwards (2000). En este sentido, lo expuesto por Nightingale y Cromby (2001) nos parece muy sugerente. Dicen que al dar un papel central al lenguaje en la construcción del mundo y el sujeto (giro lingüístico) se pasaron por alto elementos importantes que enumeran de la siguiente manera: a) La influencia de factores encarnados o incardinados (el cuerpo). El cuerpo es, para los autores, el lugar íntimo donde la naturaleza y la cultura se encuentran.

b) La materialidad (del mundo). La materialidad importa -dicen- tanto porque crea posibilidades para la acción social, como porque la constriñe.

c) El poder. En este sentido, explican, los socioconstruccionistas se olvidaron, en mayor o menor medida, del análisis postestructuralista. Y, por el contrario, Foucault (1976) había puesto especial interés tanto en el cuerpo como en la materialidad al llevar a cabo su análisis sobre la genealogía del poder.

Cada uno de estos factores se relaciona con el tema central de nuestro ensayo: el cuerpo. La idea es que éste enfoque que se centra en el lenguaje podría seguir manteniendo a la mente por encima del cuerpo, o simplemente pasando éste por alto. Por el contrario, lo que estas posturas reclaman es voltear hacia el cuerpo y considerarlo como algo central en el estudio del sujeto. Veamos qué sugieren las feministas.

\section{Hacia una Subjetividad Encarnada}

\section{Aportes feministas y postfeministas}

Consideramos que los trabajos feministas y post-feministas pudieran ser muy sugerentes porque ofrecen un puente para unir las aportaciones tanto del sociocontruccionismo como del postestructuralismo, pues en general este tipo de pensadoras son herederas de ambas tradiciones y las han logrado conjugar bien. Así, cuando Foucault (1976) nos advierte que el poder atraviesa los cuerpos muchas de estas feministas pudieron establecer dicho puente, pues sabían que el género atraviesa los cuerpos y que el género es una construcción social ${ }^{2}$.

Ahora bien, lo que nos parece muy interesante y quizá aun más innovador son los cuestionamientos que se hacen teóricas como Butler (1993), quien lo primero que se pregunta es si hay algún modo de vincular la cuestión de la materialidad del cuerpo con la performatividad del género, es decir, la práctica reiterativa y referencial mediante la cual el discurso produce los efectos que nombra sobre el cuerpo. O, en sus propias palabras: "las normas reguladoras del "sexo" obran de una manera preformativa para constituir la materialidad de los cuerpos y, más específicamente, para materializar el sexo del cuerpo, para materializar la diferencia sexual en aras de consolidar el imperativo heterosexual" (p. 18).

$\mathrm{Y}$, según la misma autora, la materialización de los cuerpos es indisociable de las normas reguladoras. El sujeto se forma al asumir un sexo. Y, este proceso que podría considerarse de identificación, implica asumir unas prácticas y excluir otras. Por eso, ella habla de la existencia de cuerpos abyectos, aquellos cuya práctica social se considera indeseable.

Y es así que asegura que las políticas feminista y queer pueden movilizar a través de prácticas que destacan la desi-

2 Y no sólo eso, sino que el sexo también lo es, tal como lo propone la teoría queer (Butler, 1993). 
dentificación con aquellas normas reguladoras mediante las cuales se materializa la diferencia sexual, lo que puede facilitar la reconceptualización de cuáles son los cuerpos que importan y qué cuerpos habrán de surgir aún como materia crítica de interés.

Por su parte McNay (1999), nos habla de otro concepto central y que es también una aportación del pensamiento feminista. Éste es el de embodiment ${ }^{3}$ porque media entre las posturas puramente físicas, simbólicas o sociológicas. Ahora el cuerpo es una frontera dinámica y mutable, es el origen, donde la experiencia vivida del mundo perteneciente a un sujeto es corporeizada y realizada, por lo cual ya no se trata más ni de un objeto puro ni de un sujeto puro.

Ahora bien, por otra parte, es interesante también la comparación que presenta López (1999) entre Butler (1993) y Bordo (1998), lo cual tiene que ver con los diferentes tipos de feminismos (razón por la cual dimos este título a este apartado). Para Bordo (1998) - dice la autora -, el cuerpo es el lugar de inscripción de los dualismos cartesianos y de un humanismo masculinizado que hace del conocimiento propiedad del varón y a la materialidad femenina. Por su parte Butler (1993), parte de Hegel y centra en el cuerpo el concepto del deseo, el cual, según ella, está basado en una creencia metafísica: la de una identidad humana prelinguïstica. Mientras Bordo quiere retener cierta materialidad sobre los cuerpos, a Butler (1993) le interesa la deconstrucción por ello fija la mirada en los cuerpos abyectos.

Aunque al final, ambas reflexiones y las que el feminismo ha generado sobre la idea de cuerpo, en especial sobre el cuerpo femenino; confluyen en una discusión que se relaciona con la idea de muerte del sujeto moderno y que apuntan hacia una nueva subjetividad, esta vez, encarnada o incardinada.

\section{Consideraciones Finales}

De todos estos hitos que hemos ido esbozando, quisiéramos señalar algunos aspectos que nos parecen relevantes para la discusión. La visión crítica sobre la tradicional dicotomía mente-cuerpo al interior del pensamiento occidental se ha convertido en una reflexión central cuando se trata de la época posmoderna o, al menos, de esta etapa crítica de la modernidad. Es decir, coincidimos con la idea de que el sujeto moderno ha muerto: ese sujeto masculino, racional, antropocéntrico, colonialista, propio de la modernidad. Y, en medio de la crisis que ello provoca, voltear la mirada hacia la corporeidad es central. Porque, si bien es cierto que el giro lingüístico dentro de la psicología social nos ha servido para superar ciertos esencialismos que sostenían a ese sujeto y con ello todo un aparato de relaciones asimétricas; también lo es que el lenguaje no es posible sin el cuerpo: el habla, como dice Heidegger (1929/2003), es la condición ontológico-existenciaria del lenguaje, es necesario que exista una semántica corporal. Sin la experiencia de seres

3 Hemos optado por no traducir el concepto porque no sabríamos como conservar su sentido de una subjetividad corporeizada o encarnada. No estamos del todo seguros de que si usamos estas palabras en castellano se entiendan igual. encarnados habitando mundos de relaciones no existiría el lenguaje tal como lo pensamos y usamos.

No obstante dentro de nuestras tradiciones, a pesar de la muerte del sujeto moderno ilustrado se mantiene cierta tendencia a la supremacía de la mente sobre el cuerpo (lo cual es más notable aún dentro de las academias científicas y universidades). Nos queda un largo trabajo reflexivo y de debate pendiente.

Pero ¿qué pasa con el sujeto ahora? ¿Qué pasa con nuestra imagen del cuerpo? La vamos reconstituyendo constantemente. Y en este sentido, las posturas feministas como las de Braidotti (2004) nos adelantan algo interesante: el sujeto femenino -pero se puede decir lo mismo de cualquier sujeto de la era posmoderna - no es más (o no debería ser) el otro ${ }^{4}$ que se define sólo en relación al sujeto importante (hombre, blanco, clase superior, etc.); sino que se convierte ahora en un devenir, en un sujeto con identidades múltiples, en constante movimiento y reinventándose con proyecciones de sentidos no sólo lingüísticos, sino también - y sobre todo - tecnológicos y/o biomédicos. Y para ello no puede hablarse de una subjetividad racional como en otros tiempos, ahora se trata de una subjetividad incardinada o encarnada, donde la identidad del sujeto no está en la mente o en el cuerpo, sino que conforman, al mismo tiempo, estos devenires.

Después de haber hecho este breve recorrido por algunos de los principales hitos en la conformación y transformación del cuerpo en nuestros contextos académicos, no quisiéramos dejar de nombrar otro hito importantísimo para nosotros, que solemos muchas veces no apreciar como parte del conocimiento científico: el del movimiento del cuerpo en las artes. La pintura, la escultura, la narrativa, la música, el teatro, el cine, incluso la arquitectura han ido creando, recreando y transformando nuestra corporeidad.

La pintura ha ido ofreciéndonos imágenes de estas transformaciones con gran claridad: la idea del cambio de épocas (gótico, barroco, renacimiento, clasicismo, realismo, impresionismo, expresionismo, cubismo, etc.) ha ido construyendo una noción aproximada de cómo entendemos nuestra corporeidad, y de cómo esta comprensión produce y reproduce pautas de comportamiento. Desde la narrativa, pudiéramos usar como ejemplo el cuento de "La metamorfosis" de Kafka. Con este cuento se aprecia muy agudamente la imposibilidad de comprender nuestras relaciones en el mundo sin una identidad encarnada.

De igual forma, ciertos procesos sociales han orientado otras formas de vivir y significar al cuerpo. Es el caso, por ejemplo, de movimientos contraculturales como el de los hippies en los años 1960. Se trataba básicamente de liberar al cuerpo de las cargas institucionalizadas y disciplinadas de un sistema que inscribía sobre las ropas, sobre el consumo, sobre la educación, sobre el trabajo el peso de unas prácticas que anulaban la creatividad, la agencialidad, el ser. Es así como se buscaba dar una respuesta de protesta contracultural al desnudarse y experimentar con drogas o

4 O el segundo sexo de Simonne de Beauvoir. 
sustancias que llevasen al cuerpo hasta otros límites fuera de lo establecido.

\section{Referencias}

Bernard, M. (1985). El cuerpo. Barcelona: Paidós.

Blumer, H. (1982). El interaccionismo simbólico: perspectiva y método. Barcelona: Hora.

Bordo, S. (1998). Material girl. Em Bordo, S. (Org.), Unbearable weight. Berkeley: University of California Press.

Bourdieu, P. (1988). La distinción. Criterios y bases sociales del gusto. Madrid: Taurus. (Trabalho original publicado em 1979)

Braidotti, R. (2004). Feminismo, diferencia sexual y subjetividad nómade. Barcelona: Gedisa.

Butler, J. (1993). Cuerpos que importan: sobre los límites materiales $y$ discursivos del "sexo". Barcelona: Paidós.

Edwards, D. (2000). Extreme case formulations: softeners, investment, and doing nonliteral. Research on Language and Social Interaction, 33(4), 347-373.

Foucault, M. (1976). Historia de la sexualidad vol. I. La voluntad de saber. México: S. XIX. (Trabalho original publicado em 1976)

Garfinkel, H. (1967). Studies in ethnomethodology. New Jersey: Prentice Hall.

Heidegger, M. (2003). ¿Qué es metafísica? Madrid: Alianza editorial. (Trabalho original publicado em 1929)
Le Breton, D. (1995). Antropología del cuerpo y modernidad. Buenos Aires: Nueva Visión.

Levy, P. (1998). ¿Qué es lo virtual? Barcelona: Paidós.

López, M. (1999). El cuerpo, el sujeto, la condición de mujer. Buenos Aires: Biblos.

McNay, L. (1999). Gender habitus and the field. Pierre Bourdieu and the limits of reflexivity. Theory, Culture and Society, 16(1), 97-117.

Merleau-Ponty, M. (1975). El filósofo y su sombra. Sobre la fenomenología del lenguaje. Madrid: Fragua.

Nightingale, D. \& Cromby, J. (2001). What's wrong with social construccionism? Em D. Nightingale \& J. Cromby (Orgs.), Social Construccionist Psychology. A critical analysis of theory and practice (pp. 35-48). Londres: London Univirsity Press.

Platón (1993). Diálogos. México: Porrúa.

Potter, J. (2000). Post-cognitive psychology. Theory and Psychology, 10(1), 31-37.

Rodríguez, R. M. (1999). Foucault y la genealogía de los sexos. Barcelona: Anthropos.

Smith, J. (1990). Psicología Social (2. ed.). Barcelona: Gedisa. 